\title{
High-Performance Acetylated loncell-F Fibers with Low Degree of Substitution
}

\author{
Shirin Asaadi, ${ }^{\dagger}$ Tia Kakko, ${ }^{\ddagger}$ Alistair W.T. King, ${ }^{\ddagger}$ Il Ilkka Kilpeläinen, $^{\ddagger}$ Michael Hummel, ${ }^{\dagger}$ \\ and Herbert Sixta*,†
}

${ }^{\dagger}$ Department of Bioproducts and Biosystems, Aalto University, P.O. Box 16300 FI-00076, Vorimiehentie 1, 02150 Espoo, Finland

${ }^{\ddagger}$ Laboratory of Organic Chemistry, Department of Chemistry, University of Helsinki, P.O. Box 55, 00014 Helsinki, Finland

\section{Supporting Information}

ABSTRACT: Cellulose acetate is one of the most important cellulose derivatives. Herein we present a method to access cellulose acetate with a low degree of substitution through a homogeneous reaction in the ionic liquid 1,5-diazabicyclo[4.3.0]non-5-enium acetate $([\mathrm{DBNH}][\mathrm{OAc}])$. This ionic liquid has also been identified as an excellent cellulose solvent for dry-jet wet fiber spinning. Cellulose was dissolved in [DBNH] [OAc] and esterified in situ to be immediately spun into modified cellulose filaments with a degree of substitution (DS) value of $0.05-0.75$. The structural properties of the resulting fibers, which are characterized by particularly high tensile strength values (525-750 MPa conditioned and 315-615 MPa wet) and elastic moduli between 10-26 GPa, were investigated by birefringence measurements, wide-angle X-ray scattering, and molar mass distribution techniques while their unique interactions with water have been studied through dynamic vapor sorption. Thus, an understanding of the novel process is gained, and the advantages are demonstrated for producing high-value products such as textiles, biocomposites, filters, and membranes.

KEYWORDS: Cellulose, Esterification, Cellulose acetate, Dry-jet wet spinning, Man-made cellulosic fibers, Ioncell-F

\section{INTRODUCTION}

The global popularity of man-made cellulose fibers (MMCFs) is rising, and the manufacturing processes are incessantly modernized. Cotton production is declining mainly because of the reduced availability of suitable arable land and partly because of the development of fibers with better color-fastness and water retention properties. It has been predicted that by 2020 the global market for MMCF will be 8.5 million tons per year with the key applications being fabrics, clothing, and spun yarns. ${ }^{1}$ In parallel to this growing demand of MMCFs, there is an increasing emphasis on a sustainable production throughout the whole value chain of fibers which includes the recycling of cellulose-based textiles and the necessity for resource saving and low-emission manufacture of fibers. ${ }^{2,3}$

The application of pulp cellulose as an ecofriendly raw material in textile manufacturing has been a step toward sustainability in the textile industry. Further, there is a growing demand for the production of functionalized textiles from renewable resources with special properties. One way to reach this goal is the development of novel strategies for the synthesis of cellulose derivatives in the course of textile fiber production. ${ }^{4}$ Among the most important commercial cellulose derivatives with a broad range of applications is cellulose acetate.

Cellulose acetate as the first organic ester of cellulose was developed by Schutzenberger in $1865 .^{6}$ Today, cellulose diacetate (CDA) with a typical degree of substitution (DS) of $2-2.7$ is the most widely used form of cellulose acetate of

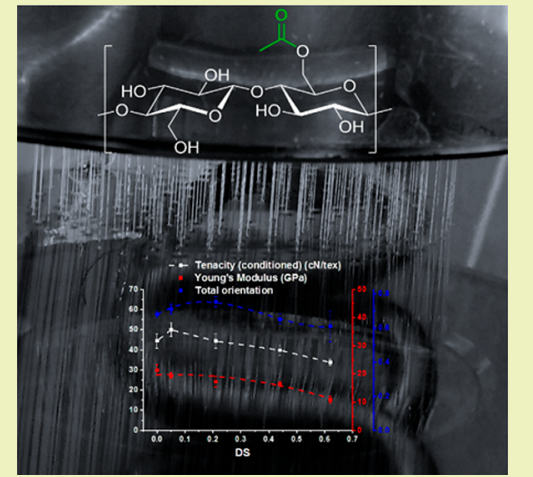

which the largest part is dry-spun to fibers for the production of cigarette filters. Further applications are in fields of coatings, films, membranes, and textile fibers. ${ }^{7,8}$

Conventional acetylation methods utilized in industry are heterogeneous processes. The commercial cellulose acetate fiber production consists of four steps: preparation of triacetate, partial hydrolysis, dissolution in acetone, and fiber spinning. It is therefore more expensive than other MMCFs, and it requires considerable amounts of toxic chemicals. ${ }^{9}$ Direct production of cellulose diacetate via heterogeneous acetylation is not possible because the distribution of acetyl groups is uneven.

However, this could be achieved through homogeneous acetylation. Meanwhile, extensive knowledge on the homogeneous derivatization of cellulose is available. ${ }^{4,10,11}$ The homogeneous esterification of cellulose has distinct advantages over the heterogeneous one due to milder reaction conditions and a more even distribution of acetate groups along the chain and within the anhydroglucose unit. ${ }^{12,13}$ For this purpose, many different cellulose solvents have been studied and developed. A few of these solvents (such as $\mathrm{N}$-ethylpyridinium chloride, 1allyl-3methyl-imidazolium chloride, $N$-methylmorpholine- $N$ oxide, $\mathrm{DMAc} / \mathrm{LiCl}$, and $\mathrm{DMSO} / \mathrm{TBAF}$ ) have the potential to be utilized for a controllable and homogeneous esterification of

Received: April 19, 2018

Revised: $\quad$ May 25, 2018

Published: May 30, 2018 
polysaccharides. In the presence of acetylation reagents (acetic anhydride, vinyl acetate, or acetyl chloride) these solvents allow for a variable adjustment of the DS from 0.3 to 3 . $^{11}$

The final properties of the cellulose acetate products depend on the distribution pattern of acetyl groups and the degree of substitution of the backbone. ${ }^{14-16}$ Cellulose acetates with a DS lower than 2.2 are not produced industrially; their properties are, however, very interesting. The aim of the new developments in this field is to understand the structure-property relationship, tailoring new cellulose products to meet the desirable properties and to decrease the chemical consumption for the production of these products. ${ }^{17}$

Studies on the application of ionic liquids (ILs) in cellulose chemistry have attracted notable commercial interest reflected by a growing number of patents, which cover all process steps from the dissolution and esterification of the cellulose to the recycling of the ionic liquid by evaporation of the precipitation agent. ${ }^{18-21}$

Ionic liquids also bear great potential for processing cellulose into value-added, shaped products such as fibers and films. ${ }^{22-25}$ They offer several advantages over existing processes such as averting the emission of volatile organic or toxic compounds in the viscose process and having a higher thermal stability than $\mathrm{N}$-methylmorpholine $\mathrm{N}$-oxide (NMMO), the solvent used in the commercial Lyocell process. NMMO is also a strong oxidant, which may initiate a side reaction that leads to the degradation of both the solvent and the dissolved cellulose. ${ }^{26}$ When aiming for the production of cellulose esters, ionic liquids can be utilized to obtain biodegradable modified fibers homogeneously in a one-step reaction with common reagents avoiding complex multistep derivatization procedures. ${ }^{13,27-29}$ It is a fast, catalyst-free reaction, and the degree of the substitution is controllable. ${ }^{30}$ However, the recyclability of the ionic liquid is still under investigation, and there are still some open questions such as on the development of energy and cost-efficient recycling strategies. $^{24}$

In this study, for the first time we report about the effect of a low degree of acetylation (DS < 1 ) on the spinnability and mechanical properties of the newly developed Ioncell-F fibers. We used a novel super-base-derived ionic liquid, namely, 1,5diazabicyclo[4.3.0] non-5-enium acetate $([\mathrm{DBNH}][\mathrm{OAc}])$, as a solvent for the homogeneous acetylation prior to dry-jet wet spinning via the Ioncell-F process. . $^{3,25}$

\section{EXPERIMENTAL SECTION}

Raw Material. Eucalyptus prehydrolysis kraft pulp from Bahia, Brazil (intrinsic viscosity, $468 \mathrm{~mL} / \mathrm{g} ; M_{\mathrm{w}}, 268.7 \mathrm{~kg} / \mathrm{mol} ; M_{\mathrm{n}}, 79.8 \mathrm{~kg}$ / mol; and polydispersity index, PDI, 3.4), has been used as a cellulose source. The pulp sheets were cut into a powder using a Wiley mill with a $1 \mathrm{~mm}$ sieve, then oven-dried to constant weight at $105^{\circ} \mathrm{C}$. The ionic liquid, 1,5-diazabicyclo[4.3.0] non-5-ene acetate $([\mathrm{DBNH}][\mathrm{OAc}])$ was synthesized at Helsinki University by slowly adding equimolar amounts acetic acid (glacial, 100\%, Merck, CAS number 64-19-7) to 1,5-diazabicyclo[4.3.0]non-5-ene (DBN, 99\%, Fluorochem, CAS number $3001-72-7)$ in a $2000 \mathrm{~mL}$ reactor at $70{ }^{\circ} \mathrm{C}$ with a constant mixing rotation speed. ${ }^{31}$ Isopropenyl acetate (IpeAc) (Sigma-Aldrich, CAS number 108-21-4) was used as acetylation agent.

Dissolution and Acetylation. The reactions were performed in a vertical kneader, where the temperature was set to $90{ }^{\circ} \mathrm{C}$ and the mixing speed to about $25 \mathrm{rpm}$. The [DBNH][OAc] was melted and weighed (either 500 or $300 \mathrm{~g}$ depending on the reaction) to the kneader, in which a vacuum-dried pulp was added within $10 \mathrm{~min}$ in an amount to reach a cellulose concentration of $13 \mathrm{wt} \%$. The pulp was dissolved within $0.5-1.0 \mathrm{~h}$, until the solution appeared clear. During the dissolution a vacuum was applied, typically $1 \mathrm{~h}$, to the vacuum system for keeping moisture out of the reaction vessel and to avoid the entrapment of air bubbles. Upon complete dissolution, the temperature was lowered to $70{ }^{\circ} \mathrm{C}$, and isopropenyl acetate (IpeAc) was added dropwise with a syringe through a septum. The reaction vessel was connected to a reflux condenser and a $\mathrm{CaCl}_{2}$-tube. After the reaction, vacuum was applied again to remove unreacted reactant and the formed side product (acetone). The reactions were carried out with different equivalents (equiv) of reactant per anhydroglucose unit of cellulose. The used equiv values were $0.75,0.5,0.25$, and 0.05 , respectively. After the reaction time $(1 \mathrm{~h})$ the reaction medium was transferred to a heated and pressurized filter unit to remove any undissolved particles.

Rheology Measurements. The rheological characteristics of the spinning solutions under shear stresses were measured. The viscoelastic behavior was studied by means of an Anton Paar MCR 300 rheometer with parallel plate geometry $(25 \mathrm{~mm}$ plate diameter, 1 mm gap size).

The dynamic frequency sweep was performed with a strain of $0.5 \%$ within the angular frequency range $0.1-100 \mathrm{~s}^{-1}$ at various temperatures from 60 to $85{ }^{\circ} \mathrm{C}$ and complex viscosity, storage, and loss moduli were recorded. The zero-shear viscosity was determined by fitting the complex viscosity data with the three-parameter Cross viscosity model assuming that the Cox-Merz rule was valid. ${ }^{32-34}$

Filament Spinning. Filament spinning was done with a laboratory spinning system (Fourné Polymertechnik) with a 36-hole multifilament spinneret, a capillary diameter of $100 \mu \mathrm{m}$, and a capillary length of $20 \mu \mathrm{m}$. The spinning temperature was between 55 and $70{ }^{\circ} \mathrm{C}$. The dope $(200 \mathrm{~g})$ was spun via $10 \mathrm{~mm}$ air gap into a cold water bath $(10-$ $15^{\circ} \mathrm{C}$ ), where the formed filament was led over a Teflon guide roller (at $20 \mathrm{~cm}$ depth) and via another guide onto a godet couple.

The rate of extrusion (Ve) was kept constant $(1.6 \mathrm{~mL} / \mathrm{min})$, and fibers with different draw ratios have been collected on the godet. Filaments have been cut out carefully with a razor blade, washed first in cold $\left(5{ }^{\circ} \mathrm{C}\right)$ and then with hot $\left(70{ }^{\circ} \mathrm{C}\right)$ water, dried, and stored under free shrinkage and controlled conditions $\left(23^{\circ} \mathrm{C}, 50 \%\right.$ relative humidity, RH) for tenacity measurements.

Acetylated fiber samples have been denoted as ACF, and the number in front of it shows the DS value. The nonacetylated fiber is shown as NACF.

Molar Mass Distribution. Molar mass distribution of the pulp and the acetylated cellulosic fibers was determined by gel permeation chromatography (GPC). Prior to the analyses, the samples were activated by a water-acetone- $\mathrm{N}, \mathrm{N}$-dimethylacetamide (DMAc) sequence. The activated samples were dissolved in $90 \mathrm{~g} / \mathrm{L}$ lithium chloride $(\mathrm{LiCl})$ containing DMAc at room temperature and under gentle stirring. The samples were then diluted to $9 \mathrm{~g} / \mathrm{L}$ in $\mathrm{LiCl} / \mathrm{DMAc}$, filtered with $0.2 \mu \mathrm{m}$ syringe filters, and analyzed in a Dionex Ultimate 3000 system with a guard column, four analytical columns (PLgel Mixed-A, $7.5300 \mathrm{~mm}$ ), RI-detection (Shodex RI-101), dual-angle light scattering, and a viscometer. A flow rate of $0.75 \mathrm{~mL} / \mathrm{min}$ was used. Narrow pullulan standards (from $343 \mathrm{Da}$ to $2500 \mathrm{kDa}$ ) were used to calibrate the system. The molar masses (MMs) of the pullulan standards are modified to correspond to those of cellulose $\left(\mathrm{MM}_{\text {cellulose }}\right.$ $\left.=q \times \mathrm{MM}_{\text {pullulan }}^{p}\right)$, as proposed by Berggren et al. ${ }^{35}$ The coefficients $q=$ 12.19 and $p=0.78$ were found by a least-squares method using the data published in their report.

The intrinsic viscosity of the pulp sample was determined in cupriethylenediamine (CED) according to the standard method SCAN-CM 15:99.

NMR Spectroscopy and Determination of Degree of Substitution. Quantitative ${ }^{31} \mathrm{P}-\mathrm{NMR}$ was performed with a Varian Unity INOVA 600 spectrometer $(600 \mathrm{MHz}$ proton frequency) equipped with a $5 \mathrm{~mm}$ direct detection broadband probe-head at 27 ${ }^{\circ} \mathrm{C}$. Quantitative ${ }^{31} \mathrm{P}$ NMR was collected with 512 transients using $90^{\circ}$ flip angle, $84000 \mathrm{~Hz}$ spectral width, $1 \mathrm{~s}$ acquisition time, and $10 \mathrm{~s}$ relaxation delay.

The determination of the degree of substitution (DS) was conducted with ${ }^{31} \mathrm{P} \mathrm{NMR}^{36}$ The free hydroxyls of the acetylated cellulose were derivatized with 2-chloro-4,4,5,5-tetramethyl-1,3,2dioxaphospholane (2-Cl-TMDP) to alkoxy-tetramethyl-1,3,2-dioxa- 
phospholanes. Some of the reactant reacts with the known amount of the internal standard (endo- $N$-hydroxy-5-norborenene-2,3-dicarboximide, $e$-HNDI), or forms the anhydride, and the rest must be visible in the spectra as such to ensure sufficient amount of the 2-Cl-TMDP. Since the DS of the reaction products was low, the solubilization of the samples was done according to Kakko et al. ${ }^{13}$

Attenuated Total Reflectance Infrared Spectroscopy (ATRIR). FTIR spectra were collected $\left(400-4000 \mathrm{~cm}^{-1}\right)$ from solid samples with a Bruker $\alpha$-P FTIR spectrometer with a diamond ATR. The ATRIR spectra were baseline corrected and normalized to the cellulose C$\mathrm{O}-\mathrm{C}$ backbone signal $\left(1010 \mathrm{~cm}^{-1}\right)$ intensity.

Mechanical Properties. The linear density (titer) was determined with a vibroscope (Vibroskop 400, Lenzing Instruments $\mathrm{GmbH} \& \mathrm{Co}$ KG) with at least $50 \mathrm{mg} /$ dtex pretension. Tenacity and elongation (wet and conditioned) were determined using a Vibrodyn 400 instrument (Lenzing Instruments $\mathrm{GmbH}$ \& $\mathrm{Co} \mathrm{KG}$ ) in both conditioned and wet state. Then, 10 fibers from each sample were tested at $23{ }^{\circ} \mathrm{C}$ and $50 \% \mathrm{RH}$. The gauge length was $20 \mathrm{~mm}$ and speed $20 \mathrm{~mm} / \mathrm{min}$ according to DIN 53816 .

The elastic modulus was determined from the slope of the stressstrain curve of the fiber in the elastic part on the basis of the ASTM D2256 standard. The stress-strain curve data was obtained from the vibroscopic measurements, and the calculation was done using MATLAB (MathWorks, Inc.).

Birefringence. Birefringence is an optical property of fibers which was determined from three selected filaments with a Zeiss Axio Scope Al microscope and a Leica B $5 \lambda$-Berek tilting compensator. Titer was measured three times with the vibroscope, permitting $1.5 \%$ variation to exclude artifacts, and the diameter was calculated assuming a density of $1.5 \mathrm{~g} / \mathrm{mL} .{ }^{37}$ During the measurement, the filaments are tensioned between two pieces of double-sided tape on a microscope slide. The optical retardation is determined in triplicate from a selected spot. Birefringence is defined as the retardation divided by the diameter; according to the literature, a birefringence of 0.062 was defined as equivalent to $100 \%$ orientation. ${ }^{38,39}$

Dynamic Vapor Sorption (DVS) Test. A dynamic vapor sorption (DVS) intrinsic apparatus (surface measurement system, London, U.K.) with a measuring accuracy of $0.1 \mu \mathrm{g}$ was used for water vapor sorption analysis of composite fibers. Approximately $10 \mathrm{mg}$ of a predried fiber bundle was added to the sample pan and preconditioned at relative humidity $(\mathrm{RH})$ of $0 \%$ at $25{ }^{\circ} \mathrm{C}$ until the equilibrium was reached using nitrogen (flow rate $100 \mathrm{~cm}^{3} / \mathrm{s}$ ). The adsorption cycle was performed in $10 \% \mathrm{RH}$ steps to a maximum of $90 \% \mathrm{RH}$. The desorption circulation employed a reverse sequence in the same manner. In both cases, the RH was kept constant until a defined equilibrium condition was reach, i.e., $\mathrm{d} m / \mathrm{d} t$ was less than $0.001 \%$ per minute over a $10 \mathrm{~min}$ period. The hysteresis of the sorption and desorption isotherms is calculated as

$$
\text { hysteresis }=\left(M_{\text {desorption }}-M_{\text {sorption }}\right) / M_{\text {sorption }}
$$

The sorption isotherms were fitted by the model developed by Hailwood and Horrobin (HH model) ${ }^{40}$ The $\mathrm{HH}$ model considers a monolayer (ML) coverage of the cellulose surface by water molecules and follows the presentation of Skaar. ${ }^{41}$ The derivation of the absorption isotherm has been explained in the experimental part of the SI.

Wide-Angle X-ray Diffraction. Wide-angle X-ray scattering experiments were carried out at the Fraunhofer Institute IAP, Golm, Germany, by means of a two-circle diffractometer (D5000, BrukerAXS) using monochromatic $\mathrm{Cu} \mathrm{K} \alpha$ radiation in symmetric transmission (with $\mathrm{Ge}(111)$ as monochromator, $\lambda=0.15406 \mathrm{~nm}$; at $30 \mathrm{~mA}$ and $40 \mathrm{kV})$. The step width $\Delta \varphi$ was $0.2^{\circ}$ with an acquisition times of $180 \mathrm{~s} / \Delta \varphi$. Scattering curves were corrected concerning absorption, polarization, Compton, and parasitic scattering. ${ }^{42,43}$ WAXS curves have been corrected and normalized. The degree of crystallinity (CrI $\%)$ and the lattice disorder parameter, $k$, were determined according to the Ruland/Vonk method. The crystallite dimensions $D(h k l)$ were evaluated via the Scherrer equation from the full width at halfmaximum of the reflections of (110), (110), and (020). The crystallite chain orientation (OG) was determined by an azimuthal scan of the meridional main interference taken from well-aligned fiber samples in the longitudinal direction. It is defined by $\left(180^{\circ}-\mathrm{FWHM}\right) / 180^{\circ}$, where FWHM is the full width at half-maximum of the (004) reflection plane. The Herman crystalline orientation factor was determined with the IAP software WAXS7. ${ }^{44}$ The average crystallite dimension was calculated from the FWHM of the lateral main peaks according to the Scherrer formula:

$$
L_{(h k l)}=0.9 \lambda /(\beta \cos \theta)
$$

\section{RESULTS AND DISCUSSION}

Dope Preparation and Spinning of the Acetylated Fibers. Prior to fiber spinning, cellulose is dissolved in the ionic liquid to yield a homogeneous solution. This offers the possibility to derivatize the polymer "in situ" as part of the dissolution step. Among different reagents for cellulose acetylation in ionic liquids studied by Kakko et al., isopropenyl acetate (IpeAc) has been identified as a fast and efficient acetylation reagent which does not require the addition of a catalyst or an additional base for achieving DS values ranging from 0.25 to $2.97 .^{13}$

Therefore, in this study, homogeneous acetylation of cellulose solution was conducted with IpeAc. Acetylated spinning dopes with DS 0.05, 0.25, 0.5, and 0.75 and cellulose content of 13 wt $\%$ were spun successfully. A nonacetylated dope with the same cellulose concentration was prepared and spun for reference. The DS of the samples was determined by ${ }^{31} \mathrm{P}$ NMR spectroscopy after fiber spinning. The spectra and results are shown in the Supporting Information in Figure S1 and Table S1, respectively. The calculated DS values from the fibrous samples were in agreement with previously reported results. ${ }^{13}$ The chosen reaction conditions resulted in conversion rates of $83-100 \%$.

Studying the viscoelastic behavior of the cellulose solution along with the molar mass distribution can provide valuable information to investigate the depolymerization of cellulose in these solutions. ${ }^{45,46}$ Additionally, the rheological properties of the spinning solution are detrimental to define the spinning window, i.e., the parameter space in which good spinnability is observed. ${ }^{25}$ The viscoelasticity of the solutions was assessed by measuring the complex viscosity and the dynamic moduli at different temperatures. The crossover point (COP) of the dynamic moduli and the zero-shear viscosity were calculated using the Cross model and assuming that the empirical CoxMerz rule is valid. ${ }^{47}$

Figure 1 shows the rheological properties from an oscillation test at $65{ }^{\circ} \mathrm{C}$. The curve in black represents the nonacetylated dope; red is the acetylated one with DS 0.05 (lowest DS), and blue is the dope containing acetylated cellulose with DS 0.75 (highest DS). The spinning temperature could be chosen according to the zero-shear viscosity and the COP of the dynamic moduli. According to several studies, high temperature during the processing of cellulose-ionic liquid solution may cause cellulose depolymerization. ${ }^{4-50}$ With increasing DS, the complex viscosity and the dynamic moduli are both decreasing which also led to a reduction of the optimum spinning temperature. The decline in viscosity can be attributed to the reduction of hydrogen bonds between the cellulose molecules through the partial substitution of the hydroxyl groups by acetyl groups. ${ }^{9}$ The increase in DS leads to a shift of the COP to higher angular frequencies and lower moduli, which is in line with previous observations by Kosan et al. ${ }^{51}$ 


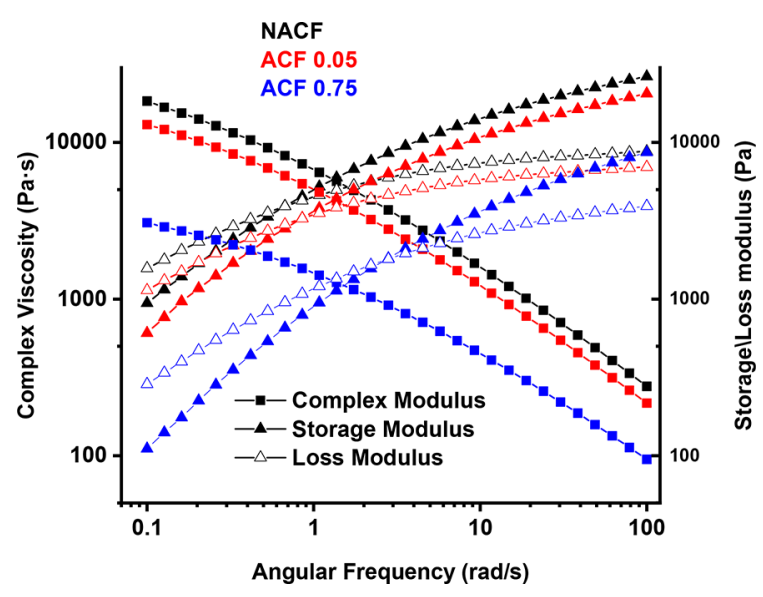

Figure 1. Rheological properties of highest and lowest DS and nonacetylated spinning dopes at $65^{\circ} \mathrm{C}$.

Rheological parameters like zero-shear viscosity and storage and loss modulus are very sensitive to any changes in molecular weight, molecular weight distribution, and chain branching. ${ }^{52}$ Figure 2a,b summarizes the results from the GPC measurement. When the MMD of the original pulp is compared with the nonacetylated fibers, a slight degradation is noted, as was also reported earlier by Michud et al. ${ }^{33}$ This degradation is even less pronounced when comparing the substrate pulp with the acetylated fibers. Thus, the above-described decrease in viscosity of the respective solutions can be assigned to the reduction of hydrogen bonds formed by cellulose and the consequent decrease in the rigidity of the cellulose chains, and it is not due to cellulose degradation. ${ }^{51,52}$ The increased flexibility of the cellulose structure results in a change of the hydrodynamic volumes of the solutes.

As mentioned earlier, all dopes were spinnable. This means that it was possible to stretch the filament and to align the cellulose molecules along the chain axis without rupture while reducing the linear density. The extent of the stretch depends on different physical and chemical parameters, which play a role when transforming a fluid filament to solid spun fibers. The viscoelastic properties of the spinning solutions must be in a defined range to reach an optimum spinnability. ${ }^{53-55}$ The acetylated spinning dopes showed zero-shear viscosities that were outside the optimum range found in our previous studies using pure cellulose solutions. ${ }^{25,56}$ The dope corresponding to DS 0.75 also had a very low dynamic modulus at the COP, which is indicative for both broadening the molecular mass distribution and lowering the stiffness/hardness or resistance to deformation. Nonetheless, the solutions showed good spinnability (Table 1), which has been defined by the maximum draw ratio (DR) that allows still for stable spinning conditions. DRs in the range between 8 and 14 denote good spinnability. ${ }^{56}$ The maximum draw ratio decreased with increasing DS. This can be explained by the reduced viscoelasticity as demonstrated by the reduced dynamic moduli and the zero-shear viscosity. It is expected that the loss in viscoelasticity of the dopes with high DS can be compensated by an increased polymer concentration (14-15 wt \%).

Physical-Mechanical Properties of the Fibers. Figure 3 compares the tenacities of fibers with different DS obtained at the same DR of 8.8 to ensure reliable comparability. An overall summary of the tensile properties of the spun fibers is listed in Table S2 and Figure S2. The data from the highest DRs of NAC and ACF 0.05 and 0.25 can be found in Table S3.

The fiber tenacity is related to the chain length of cellulose, the degree of crystallinity, and the degree of total orientation. ${ }^{57}$ When comparing the tenacities at DR 8.8, the fiber with DS 0.05 has the highest conditioned tenacity, while the nonacetylated fiber shows the highest wet tenacity. When comparing tenacities regardless of the DR, the highest conditioned tenacity has been observed for DS 0.05 (50.8 $\mathrm{cN} /$ tex) and the highest wet tenacity observed for nonacetylated fiber $(44.3 \mathrm{cN} /$ tex $)$. Overall, a decrease of the tensile strength with increasing DS can be noted. The decrease in tensile strength with increasing DS can be explained by a change of the orientation of the cellulose chains, particularly in the amorphous region (Table S4).

With an increasing amount of acetate groups attached to the cellulose chains, the molecular and supramolecular structures of the fibers are changing. The lateral chain-chain interaction is distorted within the plane and between the sheets.' Consequently, the alignment of the cellulose chain along the
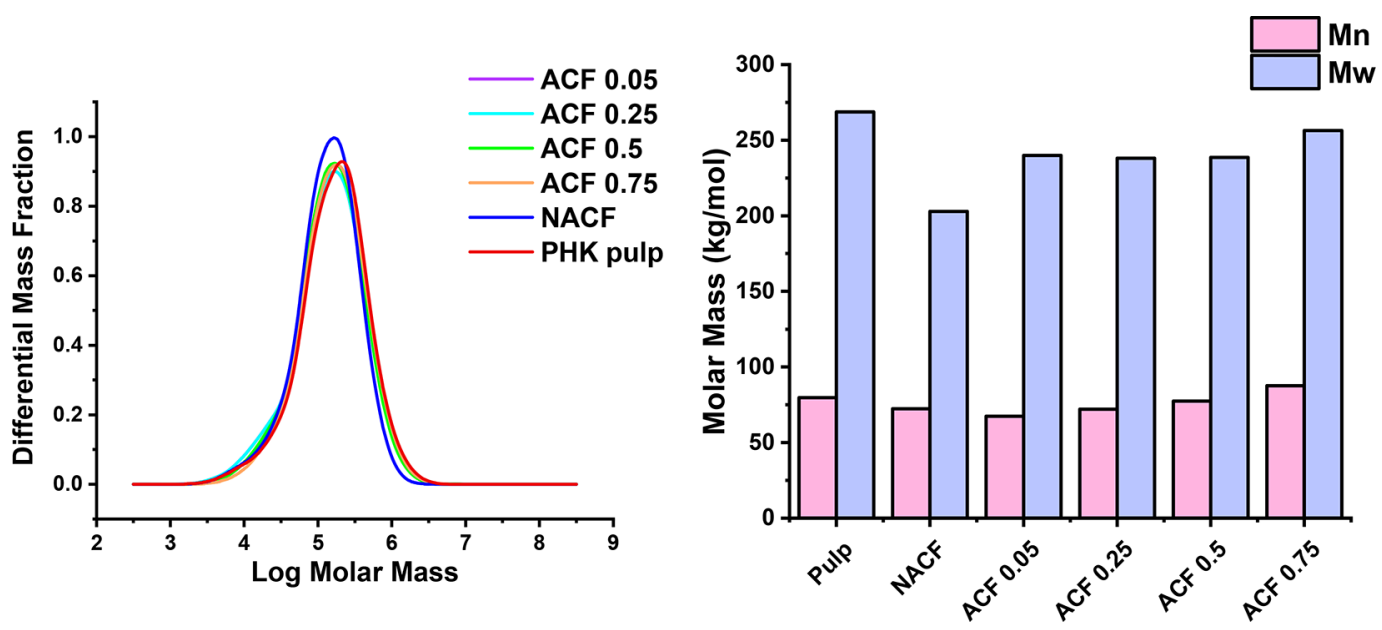

(a)

(b)

Figure 2. (a) Molar mass distribution and (b) molecular weight changes of acetylated fibers (ACFs), nonacetylated fiber (NACF), and the substrate pulp. 
Table 1. Analytical Data of Original Cellulose Pulp and Acetylated and Reference Spun Fibers

\begin{tabular}{|c|c|c|c|c|c|c|c|c|c|c|}
\hline sample & $\begin{array}{l}\text { dope cellulose } \\
\text { content, wt } \%\end{array}$ & $\begin{array}{c}\text { amount of IpeAc, }{ }^{a} \\
\text { equiv }\end{array}$ & PDI & $\begin{array}{c}M_{\mathrm{w}} \\
\mathrm{kg} / \mathrm{mol}\end{array}$ & DS & $\eta_{0}, \mathrm{~Pa} \mathrm{~s}$ & $\omega, \mathrm{s}^{-1}$ & $\begin{array}{l}\text { modulus at } \\
\mathrm{COP},{ }^{b} \mathrm{~Pa}\end{array}$ & $\begin{array}{l}\text { spinning } \\
\text { temperature, }\end{array}$ & $\begin{array}{l}\max \text { draw } \\
\text { ratio }\end{array}$ \\
\hline PHK pulp & & & 3.4 & 268.7 & & & & & & \\
\hline $\mathrm{NACF}^{a}$ & 13 & 0 & 2.8 & 203 & 0 & 26102 & 0.66 & 3908 & 68 & 14.1 \\
\hline $\mathrm{ACF}^{a} 0.05$ & 13 & 0.05 & 3.6 & 239.9 & 0.05 & 18148 & 0.83 & 3244 & 68 & 12.4 \\
\hline ACF 0.25 & 13 & 0.25 & 3.3 & 238.1 & 0.21 & 17827 & 0.85 & 3301 & 65 & 14.1 \\
\hline ACF 0.5 & 13 & 0.5 & 3.1 & 238.7 & 0.44 & 10613 & 0.98 & 2959 & 58 & 8.8 \\
\hline ACF 0.75 & 13 & 0.75 & 2.9 & 256.5 & 0.62 & 7000 & 1.31 & 1733 & 56 & 8.8 \\
\hline
\end{tabular}

${ }^{a} \mathrm{NACF}$, nonacetylated cellulose fibers; ACF, acetylated cellulose fiber; PDI, polydispersity index; IpeAc, isopropenyl acetate. ${ }^{b} \mathrm{COP}$, crossover point.

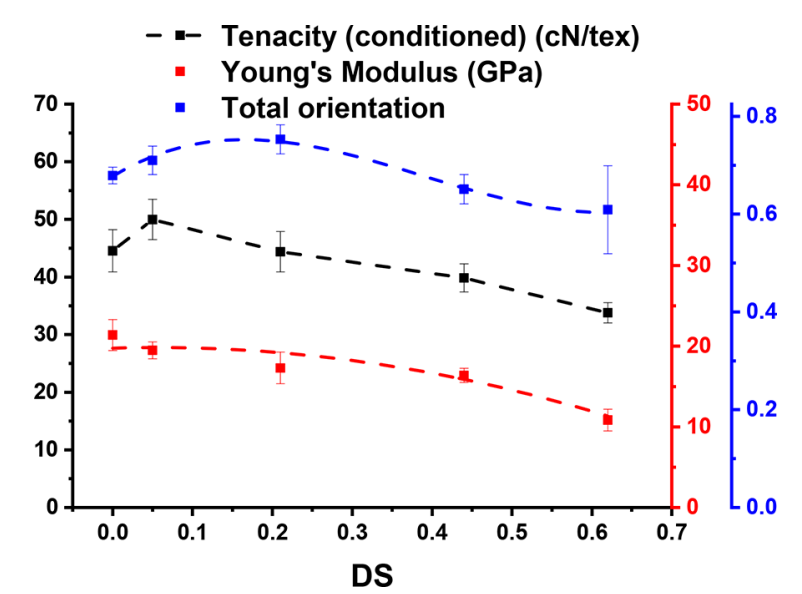

Figure 3. Tenacity, total orientation, and Young's moduli of NACF and ACF $0.05-0.75$ at DR 8.84 .

molecular axis is disturbed which is reflected in a decline of the total orientation at higher DS values (Figure 3). However, the contrary can be observed for fibers with low degrees of acetylation (0.05 and 0.25 ) where the acetyl groups seem to increase the total orientation under draw as confirmed by a higher birefringence, tenacity, and elastic modulus. At their highest draws, the DS0.05 and DS0.25 fibers reveal higher tenacities and elastic moduli than the nonacetylated fibers (Figure 4). This may be explained by a more oriented fiber network as made evident by a higher birefringence (Figure 3 ). The development of orientation is mainly from the amorphous regions, calculated from the total (birefringence) and crystalline orientation (WAXS). It seems that the cellulose molecules substituted with a low degree of acetyl group can be easier

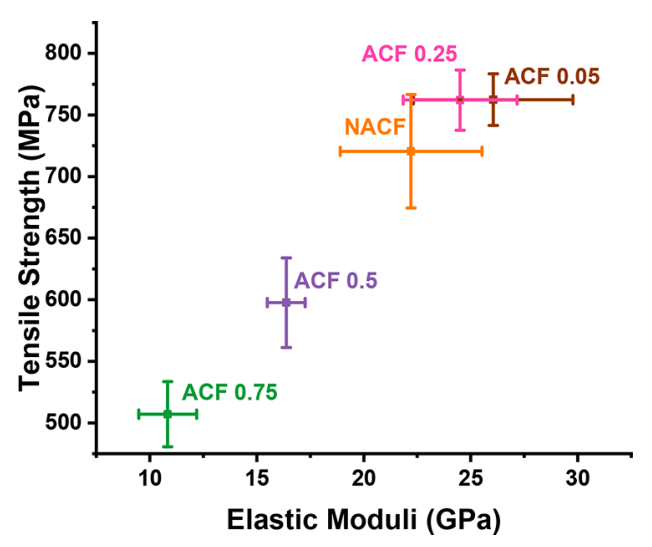

Figure 4. Tensile strength vs elastic moduli of NACF and ACF 0.050.75 at the highest draw ratios. aligned along the molecular axis by stretching in the amorphous zones due to a decreased hydrogen bond interaction between the chains (lower stiffness). However, in the case of a higher degree of acetylation, DS 0.5 and higher, the increasing steric hindrance through the attached acetyl groups impairs the alignment of the molecules along the molecular axis.

According to our previous studies on the structure of Ioncell$F$ fibers without modification, the amorphous orientation is very sensitive toward the draw ratio in particular at lower draw ratios. However, the crystalline orientation varies only a little upon changes in the DR. ${ }^{25,58}$ This was also observed for the acetylated Ioncell-F in this study (Figure S3). These results are in line with the decrease of the crystallinity and also the decrease in crystallite sizes. All the acetylated and nonacetylated fibers show the typical cellulose II WAXS diffraction pattern (Figure S4). ${ }^{59,60}$

The average crystallite dimensions were calculated using the Scherrer equation (eq 2). The crystallite size of the $1 \overline{1} 0$ and 020 lattice planes showed a clear decrease for the fibers with a higher acetylation degree ( 0.5 and 0.75$)$, while the size of the 110 lattice plane remained on the same level, independent from the DS (Table S5 and Figure S5).

Acetylation studies on cellulose I observed a similar decrease in the $1 \overline{1} 0$ crystallite size as a function of the DS. ${ }^{61,62}$ This was explained by a decrease in the direction perpendicular to the wider surface which indicates that acetylation proceeds from the surface of the microfibrils, leaving the core unreacted. Since the solution structure at high polymer concentration can be described as aggregate solution, ${ }^{63}$ it cannot be ruled out that the acetylation reaction follows a similar pattern as compared under heterogeneous conditions.

Additionally the scanning electron microscopy (SEM) images have shown that the fibrillar structure is not much affected through the acetylation; a slight decrease of the ordered structure toward ductility can be observed at high DS (Figure S6).

The wet-to-dry tenacity ratio provides a good estimation on the proportion of accessible hydrogen bonds in the amorphous region. $^{64}$ The highest wet-to-dry ratio was found for the nonacetylated samples and decreased as the DS increased (Table S2), indicating that the hydrogen bond network is disrupted in the amorphous region in wet state. The values are in good agreement with values of Ioncell-F fibers reported previously. $^{25}$

Cellulose-Water Interactions. Cellulose-water interaction is an important property in textile fiber applications. The water sorption behavior of the fibers provides further information on their structure and depends on factors such as chemical composition, orientation, and morphology. ${ }^{65-67}$ In cellulose derivatives, the moisture regain depends on the nature 
Table 2. Results from the Hailwood-Horrobin Water Monolayer (HH-ML) Model for Sorption $\left(\mathrm{HH}-\mathrm{ML}_{\mathrm{s}}\right)$ and Desorption $\left(\mathrm{HH}-\mathrm{ML}_{\mathrm{d}}\right)$ of Acetylated Ioncell-F Fibers at DR 5.3

\begin{tabular}{|c|c|c|c|c|c|c|c|c|c|}
\hline \multirow[b]{2}{*}{ sample } & \multirow{2}{*}{$\begin{array}{c}\text { sorption } \\
\begin{array}{c}\text { monolayer water }(\mathrm{ML}) \\
(\mathrm{g} / \mathrm{g})\end{array}\end{array}$} & \multirow{2}{*}{$\frac{\text { desorption }}{\text { monolayer water }(\mathrm{ML})}$} & \multirow[b]{2}{*}{ hysteresis, \% } & \multirow{2}{*}{$\begin{array}{c}\text { sorption } \\
\begin{array}{c}\text { surface area, } \\
\mathrm{m}^{2} / \mathrm{g}\end{array}\end{array}$} & \multirow{2}{*}{$\begin{array}{c}\text { desorption } \\
\begin{array}{c}\text { surface area, } \\
\mathrm{m}^{2} / \mathrm{g}\end{array}\end{array}$} & \multicolumn{2}{|c|}{ sorption } & \multicolumn{2}{|c|}{ desorption } \\
\hline & & & & & & $\begin{array}{c}\Delta G_{\mathrm{h}}{ }^{a} \\
\mathrm{~J} / \mathrm{g}\end{array}$ & $\begin{array}{c}\Delta G_{\mathrm{d}}{ }^{a} \\
\mathrm{~J} / \mathrm{g}\end{array}$ & $\begin{array}{c}\Delta G_{\mathrm{h}}, \\
\mathrm{J} / \mathrm{g}\end{array}$ & $\begin{array}{c}\Delta G_{\mathrm{d}}, \\
\mathrm{J} / \mathrm{g}\end{array}$ \\
\hline NACF & 0.0618 & 0.0783 & 27 & 186 & 235 & -203 & 33 & -241 & 47 \\
\hline ACF 0.05 & 0.0651 & 0.0864 & 33 & 195 & 259 & -164 & 34 & -228 & 54 \\
\hline ACF 0.25 & 0.0728 & 0.0906 & 25 & 218 & 272 & -134 & 37 & -220 & 53 \\
\hline ACF 0.5 & 0.0804 & 0.0943 & 17 & 241 & 283 & -112 & 39 & -215 & 52 \\
\hline ACF 0.75 & 0.0674 & 0.0923 & 37 & 202 & 277 & -177 & 32 & -188 & 51 \\
\hline
\end{tabular}

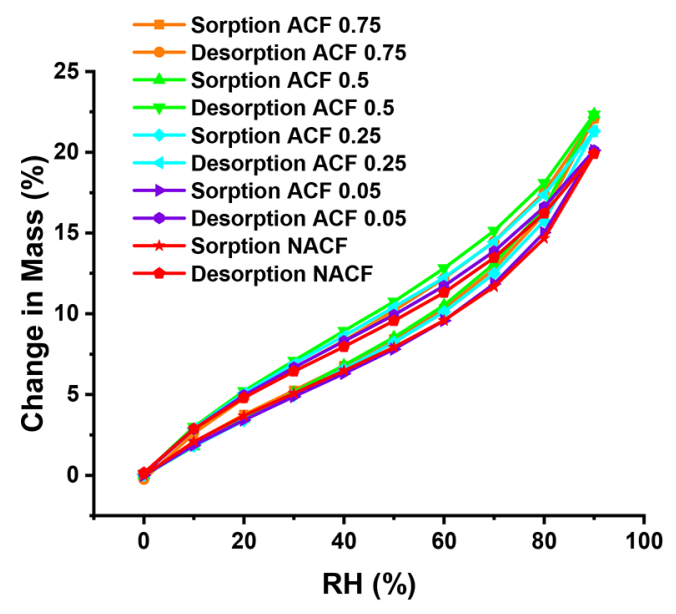

(a)

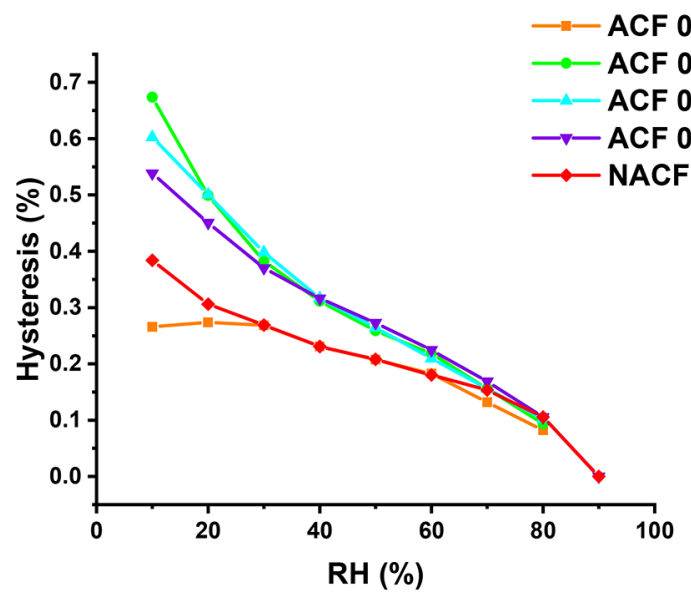

(b)

Figure 5. (a) Equilibrium moisture sorption-desorption (b) Hysteresis versus relative humidity (RH) of acetylated and nonacetylated fibers at DR 5.3.

of the substituents, their distribution along the cellulose chain, and the degree of crystallization. ${ }^{68}$ The hygroscopic behavior of the fibers was studied using the dynamic vapor sorption (DVS) test.

The Hailwood-Horrobin model is suitable to analyze the sorption-desorption of water by regenerated cellulose fibers. ${ }^{40,41}$ This model conformed when studying the effect of DR on the sorption-desorption behavior of Ioncell-F fibers. It showed that the increase of orientation causes a decrease in water-accessible surface area of the fibers. ${ }^{58}$

The water monolayer $(\mathrm{ML})$ value approximates the specific surface area based on the amount of water in contact with solid matrix. ${ }^{69,70}$ Table 2 contains the respective values for the acetylated and nonacetylated Ioncell-F fibers in sorption ( $\mathrm{HH}-$ $\mathrm{ML}_{\mathrm{s}}$ ) and desorption $\left(\mathrm{HH}-\mathrm{ML}_{\mathrm{d}}\right)$ cycles. Acetylation until DS 0.5 increases the amount of $\mathrm{HH}-\mathrm{ML}_{\mathrm{s}}$ and $\mathrm{HH}-\mathrm{ML}_{\mathrm{d}}$ whereupon at DS 0.75 these values are decreasing. This can be attributed to an increase in accessible surface area correlating to the decrease of crystallinity. These results are consistent with the change of crystallinities as a function of DS from WAXS. Until DS 0.5 the crystallinities are decreasing while at DS 0.75 the crystallinity is increasing slightly (Table S5).

The $\mathrm{HH}$ constants $K_{\mathrm{h}}$ and $K_{\mathrm{d}}$ are used to calculate the free energy changes $\Delta G_{\mathrm{h}}$ and $\Delta G_{\mathrm{d}}$, for the hydrated and dissolved water, respectively, compared with liquid water (Figure S7 and Table S6). The magnitude of the free energy change for the hydrated water, $\Delta G_{\mathrm{h}}$, and dissolved water, $\Delta G_{\mathrm{d}}$, are smaller for sorption than desorption (Figure S7). The biggest change in the free energies has been reported for nonacetylated fibers, which shows imperfect accessibility of the water molecules. ${ }^{58}$

Figure 5a,b shows the sorption-desorption cycle and the corresponding hysteresis trend for different DSs at DR 5.3. The highest and lowest hysteresis values at low relative humidity (less than 30\%) have been recorded for fibers with DS 0.5 (ACF 0.5) and DS 0.75 (ACF 0.75), respectively. The high hysteresis values of acetylated samples, except DS 0.75 , indicate a noticeable structural change that happens during the sorption course. These high values show the unstable structure of these fibers. ${ }^{67,71}$ The high initial slope at the hysteresis curve for fibers with $\mathrm{DS}<0.75$ shows that the structural changes are more significant at dry state than at wet state. A significant region for water adsorption is the less ordered amorphous parts of the fibers. ${ }^{72}$ Additionally, surface and pore sorption contribute to the overall water uptake, as for Lyocell fibers for which the open surfaces are the main sites for water sorption. ${ }^{71}$ This trend is in line with results from several previous studies. $^{51,73}$ In the desorption phase, all fibers behave similarly to those in the sorption phase.

The increase of moisture sorption at low DS is proportional to the amount of available hydroxyl groups. This implies that at higher DS, when more hydroxyl groups are substituted, moisture sorption is reduced. ${ }^{68}$ In summary, for lower DS, the moisture regain increases because of higher surface area and more accessible hydroxyl groups. In contrast, by decrease of the surface area and hydroxyl groups at higher DS, fibers develop hydrophobicity. 


\section{CONCLUSION}

During the past few years, the Ioncell-F process revealed a steady progress in the development of the process technology for the production of high-quality regenerated cellulosic fibers. For the first time, acetylated cellulose fibers with various degrees of substitution have been successfully spun from a dope, which was prepared in a one-stage process through combined dissolution and acetylation without using any catalyst. The acetylation and spinning process did not degrade the cellulose, and all the fibers demonstrated the cellulose II crystal structure.

The mechanical properties such as the elastic modulus and the conditioned tenacity of fibers can be improved through acetylation with low degrees of substitution (DS < 0.5) causing an increase in the total orientation. However, at higher DS values ( $D S \geq 0.5$ ) the resulting fibers show lower tenacity presumably due to the decrease in amorphous orientation.

The hydrophilicity of the fibers increased by acetylating the spinning dope up to DS 0.5. By a further increase of DS, the fibers become more hydrophobic. This behavior should be considered when further chemical after-treatments are needed.

High-quality modified regenerated cellulose textile or technical fibers can be produced by homogeneous derivatization. The degree of substitution is controllable and can be tailored according to the desirable properties using an environmentally friendly method.

\section{ASSOCIATED CONTENT}

\section{S Supporting Information}

The Supporting Information is available free of charge on the ACS Publications website at DOI: 10.1021/acssuschemeng.8b01768.

Additional experimental details and data including ${ }^{31} \mathrm{P}$ NMR spectra, tensile properties, orientation crystallinity and OG, WAXS pattern, crystallite size, and $\mathrm{HH}$ model from DVS data (PDF)

\section{AUTHOR INFORMATION}

\section{Corresponding Author}

*E-mail: Herbert.sixta@aalto.fi. Phone: +35850384764.

\section{ORCID}

Shirin Asaadi: 0000-0002-9848-2321

Alistair W.T. King: 0000-0003-3142-9259

Herbert Sixta: 0000-0002-9884-6885

\section{Author Contributions}

The manuscript was written through contributions of all authors. All authors have given approval to the final version of the manuscript.

\section{Notes}

The authors declare no competing financial interest.

\section{ACKNOWLEDGMENTS}

This study was conducted within the Design driven World of Cellulose program funded by the Business Finland (former TEKES).

\section{ABBREVIATIONS}

ACF, acetylated cellulose fiber; CDA, cellulose diacetate; COP, crossover point; CTA, cellulose triacetate; DS, degree of substitution; DVS, dynamic vapor sorption; $\mathrm{HH}$ model, Hailwood-Horrobin model; IL, ionic liquid; IpeAc, isopro- penyl acetate; ML, monolayer; MMCF, man-made cellulosic fibers; NACF, nonacetylated cellulose fiber; SEM, scanning electron microscopy; WAXS, wide-angle X-ray diffraction

\section{REFERENCES}

(1) Cellulosic Man-Made Fibres-A Global Strategic Business Report MCP-6407; Global Industry analysts Inc., 2016.

(2) Strähle, J.; Müller, V. Key aspects of sustainability in fashion retail. Green Fashion Retail. Springer Series in Fashion Business. 2017, 726.

(3) Shen, B.; Li, Q.; Dong, C.; Perry, P. Sustainability Issues in Textile and Apparel Supply Chains. Sustainability 2017, 9 (9), 1592.

(4) Heinze, T.; Liebert, T. Unconventional methods in cellulose functionalization. Prog. Polym. Sci. 2001, 26, 1689-1762.

(5) Varshney, V.; Naithani, S. Chemical functionalization of cellulose derived from nonconventional sources. In Cellulose Fibres: Bio-and Nano-Polymer Composites; Kalia, S., Kaith, B. S., Kaur, I., Eds.; Springer Science \& Business Media, 2011; pp 43-60, DOI: 10.1007/978-3642-17370-7.

(6) Curtis, L. G.; Crowley, J. D. Cellulose acetate and related esters. In Applied polymer science; Tess, R. W., Poehlein, G. W., Eds.; ACS Symposium Series 285; American Chemical Society: Washington, DC, 1985; pp 1053-1072, DOI: 10.1021/bk-1985-0285.ch043.

(7) Fischer, S.; Thümmler, K.; Volkert, B.; Hettrich, K.; Schmidt, I.; Fischer, K. Macromolecular Symposia; Wiley Online Library. Macromol. Symp. 2008, 262, 89-96.

(8) Glasser, W. G. Prospects for future applications of cellulose acetate. In Macromolecular symposia; Wiley Online Library: 2004; Vol. 208, pp 371-394, DOI: 10.1002/masy.200450416.

(9) Schaller, J.; Meister, F.; Schulze, T.; Krieg, M. Novel Absorbing Fibres Based on Cellulose Acetate. Lenzinger Ber. 2013, 91, 77-83.

(10) Fischer, S.; Thümmler, K.; Pfeiffer, K.; Liebert, T.; Heinze, T. Evaluation of molten inorganic salt hydrates as reaction medium for the derivatization of cellulose. Cellulose 2002, 9, 293-300.

(11) Edgar, K. J.; Buchanan, C. M.; Debenham, J. S.; Rundquist, P. A.; Seiler, B. D.; Shelton, M. C.; Tindall, D. Advances in cellulose ester performance and application. Prog. Polym. Sci. 2001, 26, 1605-1688.

(12) Heinze, T.; Liebert, T.; Koschella, A. Esterification of polysaccharides; Springer Science \& Business Media: Germany, 2006; pp 41-112, DOI: 10.1007/3-540-32112-8.

(13) Kakko, T.; King, A. W.; Kilpeläinen, I. Homogenous esterification of cellulose pulp in [DBNH][OAc]. Cellulose 2017, 24 (12), 5341-5354.

(14) Kamide, K.; Saito, M. Effect of total degree of substitution on molecular parameters of cellulose acetate. Eur. Polym. J. 1984, 20, 903-914.

(15) Iijima, H.; Kowsaka, K.; Kamide, K. Determination of sequence distribution of substituted and unsubstituted glucopyranose units in water-soluble cellulose acetate chain as revealed by enzymatic degradation. Polym. J. 1992, 24, 1077-1097.

(16) Miyamoto, T.; Sato, Y.; Shibata, T.; Tanahashi, M.; Inagaki, H. ${ }^{13} \mathrm{C}$-NMR spectral studies on the distribution of substituents in watersoluble cellulose acetate. J. Polym. Sci., Polym. Chem. Ed. 1985, 23, 1373-1381.

(17) Klemm, D.; Heublein, B.; Fink, H.; Bohn, A. Cellulose: fascinating biopolymer and sustainable raw material. Angew. Chem., Int. Ed. 2005, 44, 3358-3393.

(18) Buchanan, C. M.; Buchanan, N. L.; Hembre, R. T.; Lambert, J. L. Cellulose esters and their production in carboxylated ionic liquids. U.S. Patent 7919631B2, 2012.

(19) Buchanan, C. M.; Buchanan, N. L. Production of cellulose esters in the Presence of a Cosolvent. U.S. Patent 20120238742A1, 2012.

(20) Buchanan, C. M.; Buchanan, N. L.; Donelson, M. E.; Gorbunova, M. G.; Kuo, T.; Wang, B. Regioselectively Substituted Cellulose Esters Produced in a Halogenated Ionic Liquid Process and Products Produced Therefrom. U.S. Patent 20100029927A1, 2010.

(21) Buchanan, C. M.; Buchanan, N. L.; Guzman-Morales, E. Regioselectively Substituted Cellulose Esters Produced in a 
Tetraalkylammonium Alkylphosphate Ionic Liquid Process and Products produced Therefrom. U.S. Patent 20100267942A1, 2010.

(22) Swatloski, R. P.; Spear, S. K.; Holbrey, J. D.; Rogers, R. D. Dissolution of cellulose with ionic liquids. J. Am. Chem. Soc. 2002, 124, 4974-4975.

(23) Feng, L.; Chen, Z. Research progress on dissolution and functional modification of cellulose in ionic liquids. J. Mol. Liq. 2008, $142,1-5$.

(24) Hummel, M.; Michud, A.; Tanttu, M.; Asaadi, S.; Ma, Y.; Hauru, L. K.; Parviainen, A.; King, A. W.; Kilpeläinen, I.; Sixta, H.; Rojas, O. Ionic Liquids for the Production of Man-Made Cellulosic Fibres: Opportunities and Challenges. Adv. Polym. Sci. 2015, 133-168.

(25) Sixta, H.; Michud, A.; Hauru, L.; Asaadi, S.; Ma, Y.; King, A. W.; Kilpelainen, I.; Hummel, M. Ioncell-F: A High-strength regenerated cellulose fibre. Nord. Pulp Pap. Res. J. 2015, 30, 43-57.

(26) Rosenau, T.; Potthast, A.; Sixta, H.; Kosma, P. The chemistry of side reactions and byproduct formation in the system NMMO/ cellulose (Lyocell process). Prog. Polym. Sci. 2001, 26, 1763-1837.

(27) Ass, B. A.; Frollini, E.; Heinze, T. Studies on the homogeneous acetylation of cellulose in the novel solvent dimethyl sulfoxide/ tetrabutylammonium fluoride trihydrate. Macromol. Biosci. 2004, 4, $1008-1013$

(28) Schenzel, A.; Hufendiek, A.; Barner-Kowollik, C.; Meier, M. A. Catalytic transesterification of cellulose in ionic liquids: sustainable access to cellulose esters. Green Chem. 2014, 16, 3266-3271.

(29) Chen, M.; Li, R.; Zhang, X.; Feng, J.; Feng, J.; Liu, C.; Shi, Q. Homogeneous Transesterification of Sugar Cane Bagasse toward Sustainable Plastics. ACS Sustainable Chem. Eng. 2017, 5, 360-366.

(30) Wu, J.; Zhang, J.; Zhang, H.; He, J.; Ren, Q.; Guo, M. Homogeneous acetylation of cellulose in a new ionic liquid. Biomacromolecules 2004, 5, 266-268.

(31) Parviainen, A.; Wahlström, R.; Liimatainen, U.; Liitiä, T.; Rovio, S.; Helminen, J.; Hyväkkö, U.; King, A.; Suurnäkki, A.; Kilpeläinen, I. Sustainability of cellulose dissolution and regeneration in 1, 5diazabicyclo [4.3. 0] non-5-enium acetate: a batch simulation of the IONCELL-F process. RSC Adv. 2015, 5, 69728-69737.

(32) Cox, W.; Merz, E. Rheology of polymer melts. A correlation of dynamic and steady-flow measurement. In International Symposium on Plastics Testing and Standardization. ASTM International, 1958; Vol. 247, pp 178-188, DOI: 10.1002/pol.1958.1202811812.

(33) Lu, F.; Cheng, B.; Song, J.; Liang, Y. Rheological characterization of concentrated cellulose solutions in 1-allyl-3-methylimidazolium chloride. J. Appl. Polym. Sci. 2012, 124, 3419-3425.

(34) Sammons, R.; Collier, J.; Rials, T.; Petrovan, S. Rheology of 1. butyl-3-methylimidazolium chloride cellulose solutions. I. Shear rheology. J. Appl. Polym. Sci. 2008, 110, 1175-1181.

(35) Berggren, R.; Berthold, F.; Sjöholm, E.; Lindström, M. Improved methods for evaluating the molar mass distributions of cellulose in kraft pulp. J. Appl. Polym. Sci. 2003, 88, 1170-1179.

(36) King, A. W.; Jalomäki, J.; Granström, M.; Argyropoulos, D. S.; Heikkinen, S.; Kilpeläinen, I. A new method for rapid degree of substitution and purity determination of chloroform-soluble cellulose esters, using 31P NMR. Anal. Methods 2010, 2, 1499-1505.

(37) Maenner, J.; Ivanoff, D.; Morley, R.; Jary, S. TENCEL - new cellulose fibres for carpets. Lenzinger Ber. 2011, 89, 60-71.

(38) Adusumalli, R.; Keckes, J.; Martinschitz, K. J.; Boesecke, P.; Weber, H.; Roeder, T.; Sixta, H.; Gindl, W. Comparison of molecular orientation and mechanical properties of lyocell fibre tow and staple fibres. Cellulose 2009, 16, 765-772.

(39) Lenz, J.; Schurz, J.; Wrentschur, E. On the elongation mechanism of regenerated cellulose fibres. Holzforschung 1994, 48, $72-76$.

(40) Hailwood, A.; Horrobin, S. Absorption of water by polymers: analysis in terms of a simple model. Trans. Faraday Soc. 1946, 42, B084-B092.

(41) Skaar, C. Hygroexpansion in Wood. In Wood-Water Relations; Springer Series in Wood Science; Springer: Berlin, Heidelberg, 1988; Vol. 283, pp 352-353, DOI: 10.1007/978-3-642-73683-4.
(42) Röder, T.; Moosbauer, J.; Fasching, M.; Bohn, A.; Fink, H.; Baldinger, T.; Sixta, H. Crystallinity determination of native cellulosecomparison of analytical methods. Lenzinger Ber. 2006, 86, 85-89.

(43) Fink, H.; Fanter, D.; Philipp, B. Röntgen-Weitwinkeluntersuchungen zur übermolekularen Struktur beim Cellulose-I-II-Phasenübergang. Acta Polym. 1985, 36, 1-8.

(44) Fink, H.; Weigel, P.; Ganster, J.; Rihm, R.; Puls, J.; Sixta, H.; Parajo, J. C. Evaluation of new organosolv dissolving pulps. Part II: structure and NMMO processability of the pulps. Cellulose 2004, 11, $85-98$.

(45) Collier, J.; Watson, J.; Collier, B.; Petrovan, S. Rheology of 1butyl-3-methylimidazolium chloride cellulose solutions. II. Solution character and preparation. J. Appl. Polym. Sci. 2008, 111, 1019-1027.

(46) Dupont, A.; Mortha, G. Comparative evaluation of sizeexclusion chromatography and viscometry for the characterisation of cellulose. Journal of Chromatography A 2004, 1026, 129-141.

(47) Hummel, M.; Michud, A.; Asaadi, S.; Ma, Y.; Sixta, H.; Tanttu, M.; Netti, E. High-tenacity textile cellulose fibres from ionic liquid solutions. Chem. Fibres Int. 2015, 65, 105-107.

(48) Wendler, F.; Kosan, B.; Krieg, M.; Meister, F. Possibilities for the physical modification of cellulose shapes using ionic liquids. Macromol. Symp. 2009, 280, 112-122.

(49) Haward, S. J.; Sharma, V.; Butts, C. P.; McKinley, G. H.; Rahatekar, S. S. Shear and extensional rheology of cellulose/ionic liquid solutions. Biomacromolecules 2012, 13, 1688-1699.

(50) Michud, A.; Hummel, M.; Haward, S.; Sixta, H. Monitoring of cellulose depolymerization in 1-ethyl-3-methylimidazolium acetate by shear and elongational rheology. Carbohydr. Polym. 2015, 117, 355363.

(51) Kosan, B.; Dorn, S.; Meister, F.; Heinze, T. Preparation and subsequent shaping of cellulose acetates using ionic liquids. Macromol. Mater. Eng. 2010, 295, 676-681.

(52) Michels, C.; Kosan, B. Contribution to dissolution state of cellulose in aqueous amine oxide characterized by optical and rheological methods. Lenzinger Ber. 2003, 82, 128-135.

(53) Michud, A.; Hummel, M.; Sixta, H. Influence of molar mass distribution on the final properties of fibres regenerated from cellulose dissolved in ionic liquid by dry-jet wet spinning. Polymer 2015, 75, 19.

(54) Ziabicki, A.; Takserman-Krozer, R. Effect of rheological factors on the length of liquid threads. Kolloid Z. Z. Polym. 1964, 199, 9-13.

(55) Ziabicki, A.; Takserman-Krozer, R. Mechanism of breakage of liquid threads. Kolloid Z. Z. Polym. 1964, 198, 60-65.

(56) Asaadi, S.; Hummel, M.; Hellsten, S.; Härkäsalmi, T.; Ma, Y.; Michud, A.; Sixta, H. Renewable High-Performance Fibres from the Chemical Recycling of Cotton Waste Utilizing an Ionic Liquid. ChemSusChem 2016, 9, 3250-3258.

(57) Krässig, H. Cellulose, structure, accessibility and reactivity; Gordon and Breach Publishers: Philadelphia, 1993; pp 43-160, DOI: 10.1002/ pola.1994.080321221.

(58) Asaadi, S.; Hummel, M.; Ahvenainen, P.; Gubitosi, M.; Olsson, U.; Sixta, H. Structural analysis of Ioncell-F fibres from birch wood. Carbohydr. Polym. 2018, 181, 893-901.

(59) French, A. D. Idealized powder diffraction patterns for cellulose polymorphs. Cellulose 2014, 21, 885-896.

(60) Langan, P.; Sukumar, N.; Nishiyama, Y.; Chanzy, H. Synchrotron $\mathrm{X}$-ray structures of cellulose $\mathrm{I} \beta$ and regenerated cellulose II at ambient temperature and $100 \mathrm{~K}$. Cellulose 2005, 12, 551-562.

(61) Sassi, J.; Chanzy, H. Ultrastructural aspects of the acetylation of cellulose. Cellulose 1995, 2, 111-127.

(62) Kim, D.; Nishiyama, Y.; Kuga, S. Surface acetylation of bacterial cellulose. Cellulose 2002, 9, 361-367.

(63) Röder, T.; Morgenstern, B. The influence of activation on the solution state of cellulose dissolved in $\mathrm{N}$-methylmorpholine- $\mathrm{N}$-oxidemonohydrate. Polymer 1999, 40, 4143-4147.

(64) Lewin, M.; Pearce, E. M. Handbook of fibre chemistry, revised and expanded; Crc press: 1998; pp 773-810.

(65) Bingham, B. A study of the fine structure of regenerated cellulose fibres. Makromol. Chem. 1964, 77, 139-152. 
(66) Kreze, T.; Malej, S. Structural characteristics of new and conventional regenerated cellulosic fibres. Text. Res. J. 2003, 73, 675684.

(67) Okubayashi, S.; Griesser, U. J.; Bechtold, T. A kinetic study of moisture sorption and desorption on lyocell fibres. Carbohydr. Polym. 2004, 58, 293-299.

(68) Zugenmaier, P. Characteristics of cellulose acetates 4.1 Characterization and physical properties of cellulose acetates; Macromolecular symposia. Macromol. Symp. 2004, 208, 81-166.

(69) Carles, J.; Scallan, A. M. The determination of the amount of bound water within cellulosic gels by NMR spectroscopy. J. Appl. Polym. Sci. 1973, 17, 1855-1865.

(70) Némethy, G.; Scheraga, H. A. Structure of water and hydrophobic bonding in proteins. I. A model for the thermodynamic properties of liquid water. J. Chem. Phys. 1962, 36, 3382-3400.

(71) Cordin, M.; Griesser, U. J.; Bechtold, T. Analysis of moisture sorption in lyocell-polypropylene composites. Cellulose 2017, 24, 1837-1847.

(72) Schurz, J.; Lenz, J.; Wrentschur, E. Inner surface and void system of regenerated cellulose fibres. Angew. Makromol. Chem. 1995, 229, 175-184.

(73) Fahmy, Y.; Mobarak, F. On the fine structure of acetylated cellulose fibres. Sven. Papperstidn. 1972, 75, 853-858. 